\title{
HERITAGE LANDSCAPE INFORMATION MODEL (HLIM): TOWARDS A CONTEXTUALISED FRAMEWORK FOR DIGITAL LANDSCAPE CONSERVATION IN CHINA
}

\author{
Chen Yang ${ }^{1}$, Feng Han ${ }^{2,}$, Hangbin $\mathrm{Wu}^{3}$, Zhuo Chen ${ }^{4}$ \\ ${ }^{1}$ Dept. of Landscape Architecture, College of Architecture and Urban Planning, Tongii University, 1239 Siping Road, Shanghai, P.R. \\ China - chen.yang@tongji.edu.cn \\ ${ }^{2}$ Dept. of Landscape Architecture, College of Architecture and Urban Planning, Tongii University, 1239 Siping Road, Shanghai, P.R. \\ China - franhanf@qq.com \\ ${ }^{3}$ College of Surveying and Geo-Informatics, Tongji University, 1239 Siping Road, Shanghai, P.R. China - hb@tongji.edu.cn \\ ${ }^{4}$ Collage of Surveying and Geo-Informatics, Tongji University, 1239 Siping Road, Shanghai, P.R. China - czhuo0916@tongji.edu.cn
}

Commission II, WG II/8

KEY WORDS: Heritage Landscape, Heritage Landscape Information Model (HLIM), Cultural Experience, China, Conservation

\begin{abstract}
:
With the repaid development of Building Information Modelling (BIM), many scholars began to explore the BIM-adaption in landscape field. Landscape Information Modelling (LIM) is the corresponding concept created and used in landscape architecture discipline. However, cultural landscape heritage, as a special cultural heritage category, have specific objectives, principles and methodologies in conservation and management. It is necessary to explore an integrated information framework to facilitate the digital management of cultural landscape information. The aim of this paper is to explore an integrated information framework, which I call a 'Heritage Landscape Information Model (HLIM)', to facilitate cultural landscape heritage practices in China. This research examined the Digital Scenic Area project as instrumental case studies to identify the main components for a HLIM. As the two major components of cultural landscape heritage, both the physical features and the non-physical landscapes experiences were identified in this paper. The large amount of intangible heritage aspects indicated the significant differences between a HLIM and a BIM. Accordingly, a conceptual framework to represent 'cultural experiences' was identified with certain categories of landscape features and attributes. In terms of technologies, firstly, this research revealed that virtual reality was the most prioritised tool used in the current landscape conservation practices in China. Secondly, the other required system includes landscape-monitoring tools and the automation office work. Lastly, a HLIM also needs to contain a special information platform for cultural and historical information. The components identified in this paper could potentially contribute to an integrated conceptual framework of HLIM in China. The conclusion identified several implications for technology development.
\end{abstract}

\section{INTRODUCTION}

The New Digital Age (Schmidt and Cohen, 2013) and ubiquitous access to information provided unprecedented opportunities for a deeper understanding and appreciation of our heritage landscapes. The rapid development of Building Information Model (BIM) inspired many scholars and organisations to explore the information modelling application in Landscape Architecture. In the research and practice of geography, scholars have made significant progresses in developing and implementing digital tools that acquire, store, analyse, and share geographic information describing specified locations on the Earth's surface (Goodchild, 2009). In cultural heritage practices, the broad application of digital tools has revolutionised the representations of heritage landscapes. Digital documents have gradually taken over the role of traditional hard copy files. Innovative and research-focused uses of digital tools have become critical issues in the global heritage conservation arena (Matero and Santana, 2010).

\footnotetext{
* Corresponding author
}

However, the current digital technologies cannot meet information requirements in the conservation and management of cultural landscape heritage. The increasing pace of landscape changes and the application of new conservation methodology demand a more comprehensive and integrated information platform to assist decision making in daily management. On the one hand, urban development pressures, uncontrolled tourism development, and climate change today mean that landscapes are changing with increasing speed (Eetvelde and Antrop, 2004). Important values and knowledge are being lost through destructive changes, which poses an unprecedented urgent request for sound information systems. On the other hand, the 'cultural landscape' methodology has greatly extended the depth and breadth of heritage conservation practices, in which heritage sites are not seen as static fabric, but are dynamic entities that are interdependent on people, social contexts, and associated natural systems (Taylor and Lennon, 2011). This new methodology needs a much more inclusive information platform. 
Therefore, the overarching aim of this paper is to explore an integrated information framework, which I call a 'Heritage Landscape Information Model (HLIM)', to facilitate heritage landscape practices in China. Although it might be too early to propose a thorough framework for HLIM, it is still worthwhile to apply the BIM-thinking to heritage landscape practices and sketch out some key features of HLIM. To achieve this aim, this paper first examined the present theories of BIM and LIM to recognise the main principles and features of an information model. Secondly, some 24 heritage landscapes in a national-level digital landscape project in China were investigated as instrumental case studies to address some key questions of HLIM in the local context. Thirdly, the findings from case studies were discussed within the framework of BIM and LIM to reveal the characteristics of HLIM. Three research questions were explored in this paper:

(1) What components of heritage landscapes should be represented in a HLIM?

(2) What information of these components should be provided by a HLIM?

(3) What are the digital technologies for a HLIM?

\section{THE MAIN FEATURES OF BIM AND LIM}

Building Information Model (BIM) concepts are an emerging technological shift within the Architecture, Engineering, Construction and Operations industry (Succar, 2009). The BIM concept and many available terms were promoted globally by the Autodesk Whitepaper published in 2002. The National Building Information Model Project Committee in the US defines BIM as:

\begin{abstract}
Building Information Modelling (BIM) is a digital representation of physical and functional characteristics of a facility. A BIM is a shared knowledge resource for information about a facility forming a reliable basis for decision during its lifecycle; defined as existing form earliest conception to demolition (NBIMS-US, 2016).
\end{abstract}

Three principles of BIM can be identified from this definition. Firstly, the main object of a BIM is facility - typically buildings and structures. BIM is an object-oriented model that must be capable of representing both the physical aspects and attributes of buildings. In a BIM, presentations of the information of facilities, including drawings, schedules, cost estimates, are all views into the same information model. Secondly, BIM is an information platform for collaboration (Autodesk, 2002). Individual team members working on the same project could use a BIM to conduct his/her task. Thirdly, the main function of BIM is to manage changes so that a change to any part of the database is coordinated in all other parts (Autodesk, 2002; Bernstein, 2005). The record of changes - who changed what, and when - is available for review in a BIM, which means BIM can maintain a history of all changes made by team members for as long as this information is useful (Autodesk, 2002). The last two principles of BIM can be applied to heritage landscapes since stakeholder collaboration and change management are also critical issues for heritage landscape management. BIM is becoming powerful in many disciplines since it is not only an integrated information system (Weygant, 2011), it is also a process (Ohio, 2010), a design method (Bentley, 2011), and even a way of thinking (Hardin, 2009).

Some scholars began to explore the application of BIM principles in Landscape Architecture (Ahmad and Aliyu, 2012; Ervin, 2001; Gill, 2013; Goldman, 2011; Zajíčková and Achten, 2013). Ervin (2001) has suggested an approach for landscape design in the form of Landscape Information Model (LIM). He pointed out the two purposes of a LIM - the visualization of the physical aspects of a landscape and the understanding of the invisible aspects of a landscape. Based on these two purposes, ontology is an essential problem of LIM. Zajíčková and Achten (2013) identified two groups of landscape components: 1) sites including terrain, ground conditions, weather, micro- and macroclimate, and so forth; 2) landscape objects including 'soft' materials such as vegetation and 'hard' materials of built objects. Similarly, Ervin (2001) proposed six essential landscape elements in combination: landform, vegetation, water, structures (including architecture and infrastructure), animals (including people), and atmosphere (including sun, wind, etc.).

However, the components of heritage landscapes are more diverse than buildings and non-heritage landscapes. Swanwick (2002) proposed a framework of landscape components from a heritage perspective. She argued that landscape is about the interaction between people and place (Swanwick, 2002). A landscape contained three categories of components, including natural components, cultural and social components, and perceptual and aesthetic components (Swanwick, 2002). In many definitions of heritage landscapes, people's perceptions and the intangible components such as memories, legends, and associations were included as significant components (Council of Europe, 2000; Engelhardt and Rogers, 2009; Swanwick, 2002; UNESCO, 2002, 2009), but these components were not covered by BIM or LIM.

In terms of technology, many software was designed and developed for buildings and were proved to be useful in BIM practices. However, BIM software is not applicable to the field of Landscape Architecture (Goldman, 2011). Currently there is no specific digital tools for landscape architects. BIM software that can be used for Landscape Architects includes Vectorsworks Landmark, Land F/X, LandCAD, Siteworks, Archi Terra, AutoCAD Civil 3D, Autodesk's Revit, Grahisoft ArchiCAD. This software must be capable of representing the physical and intrinsic properties of a landscape. Among these tools, only ArchiCAD and Autodesk's Revit were tested to be more useful in Landscape Architecture tasks (Appleton et al. 2002; Paar, 2006; Wissen-Hayek et al. 2011). However, these technologies and software were mainly developed for design purpose, which cannot be directly used for management.

Some digital tools and information systems have been developed for cultural heritage and heritage landscapes. For example, Arches is an open source software platform freely available to cultural heritage organizations to help inventory and manage their heritage places (Getty Conservation Institute, 2016). It was a GIS-based platform developed jointly by the Getty Conservation Institute and World Monuments Fund. Conservation authorities using Arches can create digital inventories that describe types, locations, extent, cultural periods, materials, and conditions of heritage sites and define the 
numerous and complex relationships among those sites (Getty Conservation Institute, 2016). However, each cultural group has its specific management goals and information requirements in heritage landscape practices. Programs like Arches cannot be a universal tool that is applicable for landscapes of different cultural groups. The lack of contextualised programs for heritage landscape management can create drawbacks. At the same time, the fragmentation of information of different components has become a major obstacle for efficient management (Yang, 2015). It is therefore necessary to establish integrated and contextualised information platforms for heritage landscapes.

This paper developed a framework of HLIM in the Chinese context. Based on the existing inventory of heritage landscapes, the key objects for a HLIM were identified in this paper. The requirements of information in local conservation practices were also explored in China. Lastly, this paper examined the technologies and facilities used in contemporary heritage landscape practices to identify the technological dimensions of HLIM.

\section{A CASE STUDY OF THE DIGITAL SCENIC AREA PROJECT IN CHINA}

Scenic and Historic Interest Area is a designated national park system established by the Chinese Central Government since 1979. Today, an entire system of 244 Scenic Aras has been nominated at the national level. Digital Scenic and Historic Interest Areas (Digital Scenic Area, DSA) was conducted by China's Construction Ministry in between 2004 and 2014. It was the first digital heritage landscape project at the national level in China. Under this program, China's Construction Ministry monitored more than 50 National Scenic Areas by remote sensing devices, and 24 pilot Scenic Areas have already built their own digital management systems (Appendix 1).

The DSA project was selected as case studies for three reasons. Firstly, the digital management programs and facilities built in the DSA project reflected contemporary information requirements in heritage landscape practices in China. The DSA project selected 24 National Scenic Areas as pilot sites to test digital information systems in supporting their daily management. Secondly, these pilot sites demonstrated the local management context of heritage landscapes. The key stakeholders of these national Scenic Areas are the potential users of HLIM. The proposed HLIM framework should be able to support the collaboration of such diverse management authorities and individuals.

Thirdly, the pilot sites within the DSA project demonstrated the characteristics of Chinese heritage landscapes. The Scenic Area system is different from the National Park systems in Western countries as China's Scenic Areas are characteristic by outstanding natural and cultural qualities (Han, 2007). Therefore, most Scenic Areas in China can be seen as heritage landscapes. In the DSA project, the pilot sites were some of the most significant heritage landscapes in China. 17 of the 24 pilot sites are World Heritage properties (Appendix 1). These sites contained nearly all kinds of components of Chinese heritage landscapes, both tangible and intangible. Therefore, the case studies of the DSA project provided a rich context to address the three research questions.
Three datasets were collected in the case study. As the major dataset, conservation documents including site files, conservation plans, and heritage register inventories were collected from local management authorities to identify the main component of Chinese heritage landscapes. Based on these documents, semi-structured interviews were conducted with key stakeholders of a National Scenic Area to investigate the information requirements at the local level. Additionally, academic papers and DSA project reviews for each site were collected from online resources to explore the technologies used for heritage landscape practices. While the data collection process was guided by specific research questions, the three datasets were finally combined to get more comprehensive answers for each problem.

Five stakeholders of Slender West Lake Scenic and Historic Interest Area were interviewed in 2014, including a site manager, a heritage expert, a landscape historian, a tour organiser, and an academic in Landscape Architecture. Each interviewee was asked to answer an open-ended question: 'In your view, what information of the landscape should managers be collecting and using to guide the future management of your site?' This question was designed to explore different stakeholders' information requirements in their working processes. Some typical phenomenographical questions, such as 'What do you mean by that?' 'Why is this important?' and 'What are you going to learn from this system?' were asked to generate more information.

A content analysis method was used to analyse conservation documents and the interview data. The main components of heritage landscape were identified from documentary evidence. The statement of heritage landscapes in conservation files and the transcriptions of interviews were imported into an N'Vivo program. Some qualitative methods - including open and axial coding, categorising, and developing themes - were used to identify the main components of heritage landscapes and the information requirement of conservation practice.

\section{RESULTS - IDENTIFYING THE KEY FEATURES OF HLIM}

Based on the case studies, an inventory of heritage landscape components was identified. Three categories of landscape components including twenty-one sub-categories were included in the statements of those pilot sites (Figure 1). It was found that, rather than the physical components, the cultural experience was described as the most important feature of China's heritage landscapes. Intangible cultural heritage was a significant component supporting these cultural experiences. Accordingly, a conceptual framework integrating both tangible and intangible components was identified (Figure 1). The major components of heritage landscapes were found very different from the objects included in BIM or LIM. Natural component and intangible cultural heritage were not covered by the present frameworks of BIM and LIM. 


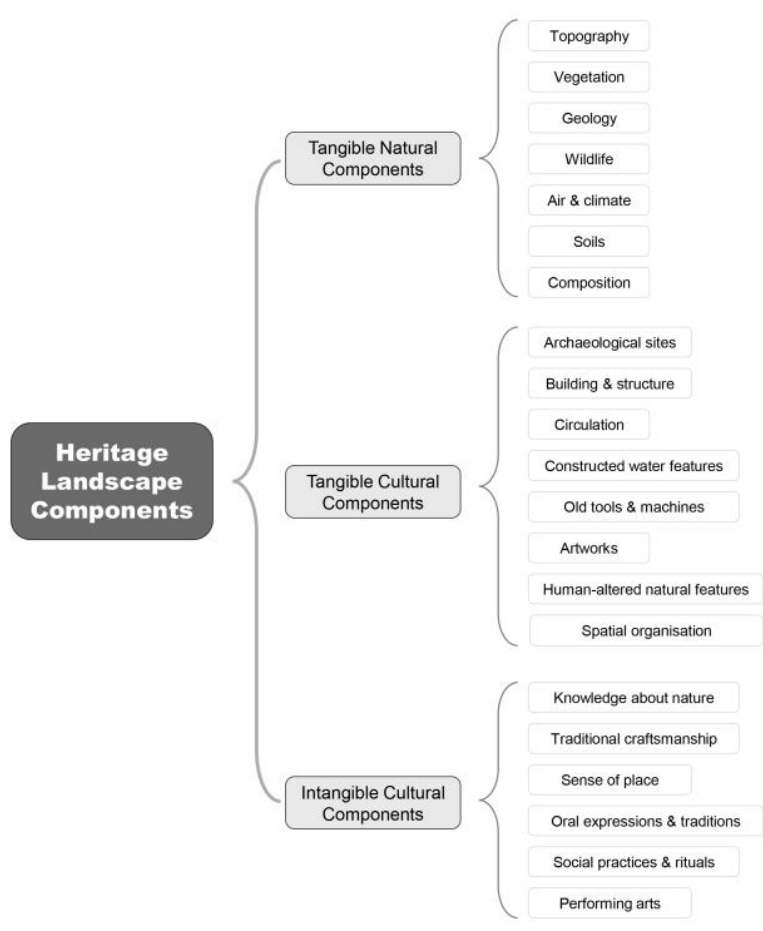

Figure 1. Heritage landscape components identified from case studies

Three themes of information requirements were identified in the case study. Firstly, rather than information of heritage landscapes, information of tourism was the largest theme, which included eight sub-categories (Figure 2). The data about tourism, such as ticket booking, tourist enquiry, and vehicle arrangement were concerned the most important information to be integrated in the information system. Secondly, the information about heritage landscape components need to be collected and represented in the information platform. Within the 24 pilot sites, only 6 of them have established cultural heritage monitoring programs and facilities. Thirdly, information of the management group was also required to be included in the information system. This was described as an information platform for management teams. Each heritage landscape is managed by a large group including many departments, institutes, and individuals. It is therefore necessary to set up an office work system into HLIM.

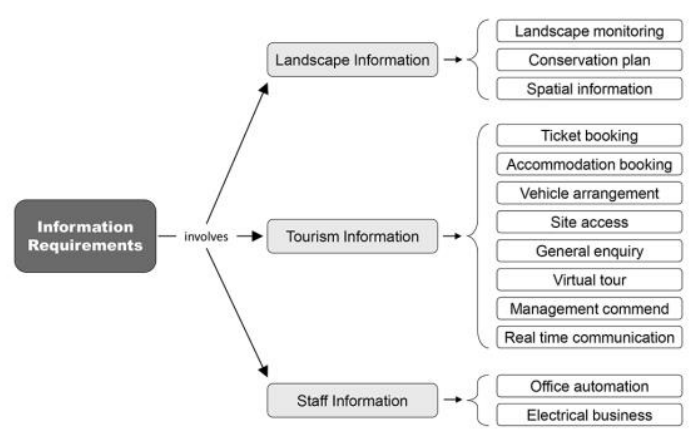

Figure 2. Information requirements of pilot Scenic Areas in China
In terms of technologies, Figure 3 demonstrates the technologies used for each pilot site and the main representing objects by different technologies. It was found that video monitoring systems were the most prioritised digital tool in the 24 pilots. Half of the pilot sites established their own video monitoring programs and facilities (Figure 3). Such systems were used for monitoring tourist, forest, and cultural heritage elements (mainly heritage buildings). Additionally, ' $3 \mathrm{~S}$ ' technologies, including Geographical Information Systems (GIS), Global Positioning System (GPS), and Remote Sensing (RS) were also a significant group in the 'toolkit' of pilot Scenic Areas. RS technologies were mainly used for monitoring the environment at a large scale. GIS was mainly used to visualise landforms and spatial analyses. GPS tools were applied for transportation including vehicle and watercraft arrangement. Among those technologies, Virtual Reality was a growing tool used mainly for providing virtual tours online. It was noticed that multimedia database started to be applied as an approach to collect and present documents of heritage landscapes (Figure 3).

\begin{tabular}{|c|c|c|c|c|c|c|c|}
\hline \multirow{3}{*}{ Pilot sites } & \multicolumn{7}{|c|}{ Technologies } \\
\hline & \multirow{2}{*}{$\begin{array}{c}\text { Video } \\
\text { Monitoring }\end{array}$} & \multicolumn{3}{|c|}{$3 \mathrm{~s}$} & \multirow{2}{*}{$\begin{array}{l}\text { Automation } \\
\text { Office Work }\end{array}$} & \multirow{2}{*}{$\begin{array}{l}\text { Virtual } \\
\text { Reality }\end{array}$} & \multirow{2}{*}{$\begin{array}{r}\text { Multimedia } \\
\text { Database }\end{array}$} \\
\hline & & RS & GPS & GIS & & & \\
\hline Great Wall & {$[h][t]$} & & & & {$[\mathrm{sm}]$} & & \\
\hline \multicolumn{8}{|l|}{ Jingyue Tan } \\
\hline Mt. Yuntai (JS) & {$[f][t]$} & & {$[v]$} & & {$[\mathrm{sm}][\mathrm{e}]$} & [ss] & \\
\hline \multicolumn{8}{|l|}{ West Lake } \\
\hline Mt. Putuo & [I] & \multirow{3}{*}{$\begin{array}{l}{[n]} \\
{[n]}\end{array}$} & \multirow{3}{*}{$\begin{array}{l}{[w]} \\
{[v]} \\
{[w]}\end{array}$} & \multirow[t]{3}{*}{ [I] } & {$[\mathrm{sm}]$} & & \\
\hline Mt. Jiuhua & {$[h]$} & & & & & & \\
\hline \multicolumn{2}{|l|}{ Mt. Wuyi } & & & & & & \\
\hline Mt. Lushan & [t] & & & & & & \\
\hline \multicolumn{3}{|l|}{ Mt. Taishan } & & & & \multicolumn{2}{|l|}{ [ss] } \\
\hline Mt. Yuntai (HN) & {$[7$} & {$[n]$} & & \multirow[t]{2}{*}{ II) } & \multirow[t]{2}{*}[\mathrm{sm}]{} & & \\
\hline \multirow{2}{*}{$\begin{array}{l}\text { Mt. Wudang } \\
\text { Mt. Heng }\end{array}$} & {$[h][f]$} & \multirow[t]{2}{*}[n]{} & \multirow[t]{2}{*}[v]{$[w]$} & & & \multirow[t]{2}{*}{ [ss] } & \\
\hline & {$[7]$} & & & & & & \\
\hline Wulingyuan & {$[t]$} & \multirow[t]{2}{*}{$\mid n]$} & & [I] & {$[\mathrm{sm}]$} & [ss] & \\
\hline Mt. Baiyun & & & \multicolumn{2}{|l|}{$[w]$} & & & \\
\hline \multicolumn{2}{|l|}{ Mt. Qingcheng } & {$[n]$} & & \multirow[t]{2}{*}{ [I] } & & & \\
\hline Mt. Emei & {$[$ [h] [f] } & {$[n]$} & {$[v]$} & & {$[\mathrm{sm}][\mathrm{e}]$} & & \\
\hline Stone Forest & & & & & & & \\
\hline Mt. Tianshan & [t] & & {$[v]$} & & & & \\
\hline Mt. Wutai & {$[h][f][t]$} & {$[n]$} & & [I] & & & \\
\hline Dujiangyan & & {$[n]$} & & & & [ss] & \\
\hline Jiuzhai Valley & & & & & & & \\
\hline LM Grottoes & & & & & & & \\
\hline Ming Tombs & & & & & & & \\
\hline ZS Mausoleum & & & & & {$[s \mathrm{sm}]$} & & {$[s s][h][t]$} \\
\hline
\end{tabular}

Figure 3 Technologies used in the DSA projects and their objects. The main object for each technology: [e]-electronic business; [f]forest; [h]-heritage; [1]-landform; [n]-natural environment; [sm]staff management; [ss]-scenic spot; [t]-tourism; [v]-vehicle; [w]watercraft

\section{CONCLUDING DISCUSSION}

BIM principles can be applied to heritage landscapes, but the ontology of BIM cannot be directly borrowed. The main components of heritage landscape in China were found very different from the objects in BIM and LIM. At the same time, the dynamic of landscape components created great challenges for HLIM. For example, plants in a heritage landscape have a very complex structure due to the changes of size, shape and appearance. These different attributes should be maintained according to specific parameters of heritage values. Only a few components such as historic buildings and infrastructures in 
heritage landscapes can be handled in the same way like BIMobjects, but the goal of management is to maintain the historical information, rather than ensuring the most effective operation.

At the same time, many intangible components such as sense of place, social practices, and traditional craftsmanship should be included into the information platform of heritage landscapes. However, representing such components has been a problematic issue in computer systems. In many digital information systems such as GIS, many intangible components of heritage landscape cannot be represented if they do not have physical carriers. For example, legends are concerned as a significant intangible cultural heritage of landscape in many cultural communities. However, many legends are not necessarily attached to specific landscape features. As the result, representing these intangible components in a HLIM is both an ethical and technical problem.

In BIM and LIM, the most required information was the data about facilities and landscapes. In contrast, the major information requirements of heritage landscapes in China was about people, rather than the built environment. Tourism information was identified the most required data in the proposed information platform, which means that there should be a model within HLIM to store and share tourism data. This special demand will be a significant feature of HLIM, and the scope of data for HLIM will be much broader than BIM and LIM. In addition to spatial and attribute data, the knowledge of the social, economic, and cultural environment related to heritage landscapes must be covered by HLIM.

Different information requirements can also be recognised through a comparison of the operational process of buildings and heritage landscapes. A heritage landscape management process is completely different from the process of building and landscape design (Figure 4). Firstly, the 'design' stage of the building/landscape lifecycle does not exist in heritage landscapes. Rather than starting from conceptions, the management of heritage landscape normally begins with a landscape assessment process; secondly, heritage landscape management is a circulation process rather than a linear process, which means that the management of heritage landscape is an unending process most physical environments of heritage landscape need to be protected forever rather than being demolished; thirdly, construction is an important phases for building project but it is not a necessary stage for heritage landscape management. All these differences mean that HLIM should be a much more complex information system that BIM or LIM.
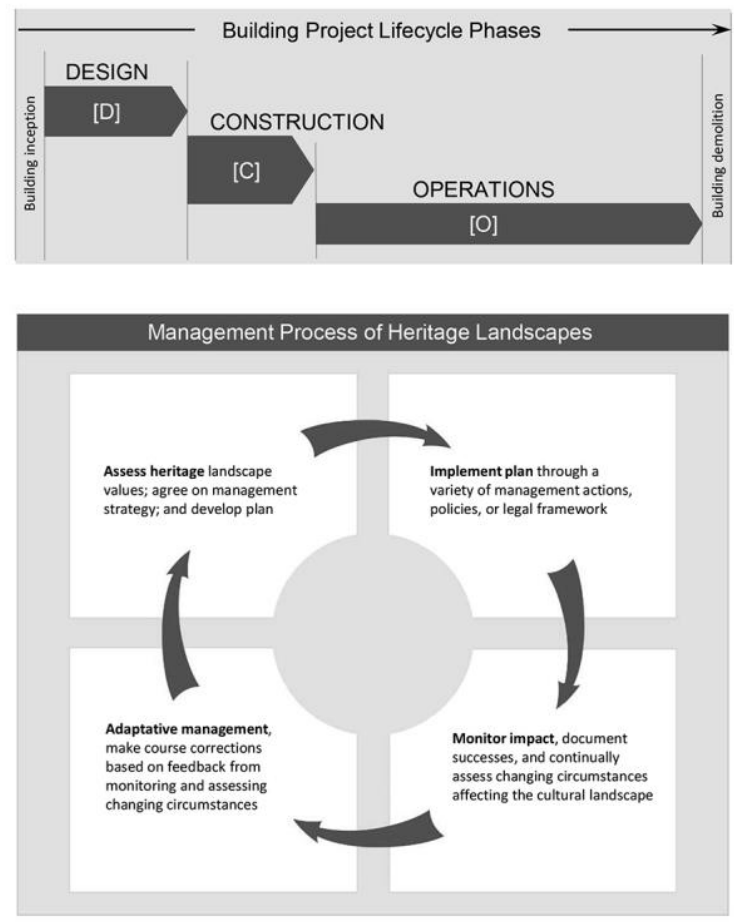

Figure 4. Building project lifecycle phases and management process of heritage landscapes (Succar, 2009; UNESCO, 2009)

It will be extremely difficult for any single software to carry out so many functions of the tools applied in heritage landscapes. In China today, tourism and heritage conservation are two separated systems. Based on the analysis of the technology used in the DSA project, it is reasonable to propose some expectations for the software of HLIM: 1) It should be a GIS based platform integrating both spatial and attribute data; 2) it should be a group of programs with each individual part has special functions but they could work together in a consistent manner; 3 ) it should be able to deal with big data, since the management of heritage landscape is an unending process; 4) it should have a userfriendly interface since a large group of stakeholders with different perspectives and backgrounds will be connected by such platform; 5) the ability of updating in such program should be powerful so that regular monitoring and documentation of heritage components will be possible; 6) it should be able to handle multimedia files so that many intangible cultural heritage could be integrated into the platform.

To conclude, it is meaningful to provide a preliminary definition of HLIM: HLIM is a digital representation of tangible and intangible components of a heritage landscape. A HLIM is a shared knowledge resources for information about a heritage landscape forming a reliable basis for decision in the management processes including heritage assessment, conservation plan, implementation, monitoring impacts and assessing changing circumstances. In the field of Landscape Architecture, both LIM and HLIM is still at the early stage. Landscape researchers and conservators should formalise this new topic so that software developer can adjust to the demands. We should actively participate in the exploration and development of HLIM to better conserve and manage our heritage landscapes. 


\section{ACKNOWLEDGEMENTS}

This research was supported by the National Natural Science Foundation of China (Youth Foundation) under Grant number 51608369; Fundamental Research Funds for the Central University (Tongji University) under Grant number 22120180065; Research Funds for the International Open Projects in the College of Architecture and Urban Planning (CAUP) in Tongji University under Grant number 2018040301.

\section{REFERENCES}

Ahmad, A. M., and Aliyu, A. A., 2012. The Need for Landscape Information Modeling (LIM) in Landscape Architecture. Paper presented at the GeoDesign, 3D Modeling and Visualization (13th Digital Landscape Architecture Conference), Bernburg.

Appleton, K., Lovett, A., Sünnenberg, G., and Dockerty, T., 2002. Rural Landscape Visualisation from GIS Databases: A Comparison of Approachs, Options and Problems. Computers, Environment and Urban Systems, 26(2-3), pp. 141-162. doi:10.1016/S0198-9715(01)00041-2.

Autodesk, 2002. Building Information Modeling. Autodesk White Paper. from www.autodesk.com/buildinginformation.

Bentley, 2011. About BIM. Retrieved from http://www.bentley.com/en-

GB/Solutions/Buildings/About+BIM.htm.

Bernstein, P., 2005. Integrated Practice: It's not just about the Technology. Retrieved from http://www.aia.org/aiarchitect/thisweek05/tw0930/tw0930bp_no tjusttech.cfm.

Council of Europe, 2000. European Landscape Convention. European Treaty Series. Florence: Council of Europe.

Eetvelde, V. V., and Antrop, M., 2004. Analyzing structural and functional changes of traditional landscapes - two examples from Southern France. Landscape and Urban Planning, 67(1-4), pp. 79-95. doi:10.1016/s0169-2046(03)00030-6.

Engelhardt, R. A., and Rogers, P. R., 2009. Hoi An Protocols for Best Conservation Practice in Asia Professional Guidelines for Assuring and Preserving the Authenticity of Heritage Sites in the Context of the Cultures of Asia.

Ervin, S. M., 2001. Digital Landscape Modeling and Visualization: A Research Agenda. Landscape and Urban Planning, 54(1-4), pp. 49-62. doi:10.1016/S01692046(01)00125-6.

Getty Conservation Institute, 2016. Arches Heritage Inventory and Management System. Retrieved from http://demo.archesproject.org.

Gill, L. R., 2013. A 3D Landscape Information Model. (Ph.D), University of Sheffield.

Goldman, M., 2011. Landscape Information Modeling.
Retrieved

from http://www.di.net/articles/archive/landscape_information_modeli ng.

Goodchild, M. F., 2009. Geographic Information Systems and Science: Today and Tomorrow. Procedia Earth and Planetary Science, 1(1), pp. 1037-1043. doi:10.1016/j.proeps.2009.09.160.

Han, F., 2007. Cross-Cultural Confusion: Application of World Heritage Concepts in Scenic and Historic Interest Areas in China. In J. B. Callicott and M. Nelson (Eds.), The Great New Wilderness Debate (Vol. 2): University of Georgia Press.

Hardin, B., 2009. BIM and Construction Management Proven Tools, Methods, and Workflows. Indiana: Wiley Publishing.

Matero, F., and Santana, M., 2010. Int'l Symposium on Heritage Recording and Information Management in the Digital Age(SMARTDoc Heritage). Retrieved from http://whc.unesco.org/en/events/637.

NBIMS-US, 2016. Frequently Asked Questions about the National BIM Standard-United States: National BIM Standard United States.

Ohio, S. O., 2010. State of Ohio Building Information Modeling (BIM) Protocol: State Architects Office, General Services Division.

Paar, P., 2006. Landscape Visualisations: Applications and Requirements of 3D Visualisation Software for Environmental Planning. Computers, Environment and Urban Systems, 30(6), pp. 815-839. doi:10.1016/j.compenvurbsys.2005.07.002.

Schmidt, E., and Cohen, J., 2013. The New Digital Age: Reshaping teh Future of People, Nations and Business. London: John Murray.

Succar, B., 2009. Building Information Modeling Framework: A Research and Dilivery Foundation for Industry Stakeholders. Automation in Construction, 18(3), pp. 357-375. doi:10.1016/j.autcon.2008.10.003.

Swanwick, C., 2002. Landscape Character Assessment Guidance for England and Scotland. Cheltenham; Edinburgh: The Countryside Agency; Scottish Natural Heritage.

Taylor, K., and Lennon, J., 2011. Cultural Landscapes: a Bridge between Culture and Nature? International Journal of Heritage Studies, 17, pp.537-554.

UNESCO, 2002. Cultural Landscapes: the Challenges of Conservation Paper presented at the World Heritage 2002, Ferrara - Italy.

UNESCO, 2009. World Heritage Cultural Landscapes: A Handbook for Conservation and Management. Paris, France: World Heritage Centre, United Nations Educational, Scientific and Cultural Organisation.

Weygant, R. S., 2011. BIM Content Development: Standards, Strategies, and Best Practices. New Jersey: John Wiley and Sons. 
Wissen-Hayek, U., Melson, J., Neuenschwader, N., Girot, C., and Grêt-Regamey, A., 2011. Interdisciplinary Studio for Teaching $3 D$ Landscape Visualisation - Lessons from the LVML. Paper presented at the The Digital Landscape Architecture Conference 2011, Berlin.

Yang, C., 2015. Using an 'Interpretative Model' for Contextual Design of Heritage Landscape Databases: The Case of St Helena Island National Park in Queensland, Australia. Geographical Research, 53(3), pp. 321-335. doi:10.1111/1745-5871.12117.

Zajíčková, V., and Achten, H., 2013. Landscape Information Model: Plants as the Components for Information Modeling. Paper presented at the Computation and Performance Proceedings of the 31 st eCADDe Conference, Delft, The Netherlands.

\section{Appendix}

Appendix 1. Categories of the pilot sites of the DSA Project

\begin{tabular}{|c|c|c|}
\hline Pilot sites & Category & $\begin{array}{c}\text { World } \\
\text { Heritage }\end{array}$ \\
\hline $\begin{array}{l}\text { The Great Wall - the } \\
\text { Badaling Section }\end{array}$ & Cultural Heritage & $\begin{array}{l}\text { Cultural } \\
\text { Heritage }\end{array}$ \\
\hline $\begin{array}{l}\text { Jingyuetan National } \\
\text { Park }\end{array}$ & $\begin{array}{c}\text { National Forest } \\
\text { Park } \\
\end{array}$ & \\
\hline $\begin{array}{l}\text { Mount Yuntai in } \\
\text { Jiangsu Province }\end{array}$ & Cultural Landscape & \\
\hline $\begin{array}{l}\text { West Lake in } \\
\text { Hangzhou }\end{array}$ & Cultural Landscape & $\begin{array}{c}\text { Cultural } \\
\text { Landscape }\end{array}$ \\
\hline Mount Putuo & $\begin{array}{c}\text { Religious } \\
\text { Landscape } \\
\end{array}$ & \\
\hline Mount Jiuhua & Cultural Landscape & Mixed Heritage \\
\hline Mount Wuyi & Cultural landscape & Mixed Heritage \\
\hline Mount Lushan & Cultural landscape & $\begin{array}{c}\text { Cultural } \\
\text { landscape }\end{array}$ \\
\hline Mount Taishan & Cultural Landscape & Mixed Heritage \\
\hline $\begin{array}{l}\text { Mount Yuntai in } \\
\text { Henan Province }\end{array}$ & Geological Park & \\
\hline $\begin{array}{l}\text { Ancient Building } \\
\text { Complex in the } \\
\text { Wudang Mountains }\end{array}$ & Cultural Landscape & $\begin{array}{l}\text { Cultural } \\
\text { Heritage }\end{array}$ \\
\hline Mount Heng, Nan Yue & Cultural Landscape & \\
\hline $\begin{array}{l}\text { Wulingyuan Scenic } \\
\text { Area }\end{array}$ & Natural Landscape & $\begin{array}{l}\text { Natural } \\
\text { Heritage }\end{array}$ \\
\hline Mount Baiyun & Cultural Landscape & \\
\hline Mount Qingcheng & $\begin{array}{c}\text { Religious } \\
\text { Landscape } \\
\end{array}$ & $\begin{array}{l}\text { Cultural } \\
\text { Heritage }\end{array}$ \\
\hline $\begin{array}{l}\text { Mount Emei Scenic } \\
\text { Area }\end{array}$ & $\begin{array}{l}\text { Religious } \\
\text { Landscape }\end{array}$ & Mixed Heritage \\
\hline Stone Forest & Ethnic Landscape & $\begin{array}{c}\text { Natural } \\
\text { Heritage }\end{array}$ \\
\hline Xinjiang Tianshan & Natural Landscape & $\begin{array}{c}\text { Natural } \\
\text { Heritage }\end{array}$ \\
\hline Mount Wutai & Cultural Landscape & $\begin{array}{l}\text { Cultural } \\
\text { Heritage } \\
\end{array}$ \\
\hline $\begin{array}{l}\text { The Dujiangyan } \\
\text { Irrigation System }\end{array}$ & National Relics & $\begin{array}{l}\text { Cultural } \\
\text { Heritage }\end{array}$ \\
\hline $\begin{array}{l}\text { Jiuzhaigou Valley } \\
\text { Scenic and Historic } \\
\text { Interest Area }\end{array}$ & $\begin{array}{c}\text { Ethnic } \\
\text { Landscape/village }\end{array}$ & $\begin{array}{l}\text { Natural } \\
\text { Heritage }\end{array}$ \\
\hline Longmen Grottoes & Cultural Heritage & $\begin{array}{l}\text { Cultural } \\
\text { Heritage }\end{array}$ \\
\hline Ming Dynasty Tombs & Cultural Heritage & $\begin{array}{l}\text { Cultural } \\
\text { Heritage }\end{array}$ \\
\hline $\begin{array}{l}\text { Sun Yat-sen } \\
\text { Mausoleum }\end{array}$ & $\begin{array}{l}\text { National AAAAA } \\
\text { Rank Tourist Area }\end{array}$ & \\
\hline
\end{tabular}

